\title{
Crisis interventions in online psychological counseling
}

\author{
Intervenções em crise nos atendimentos psicológicos online
}

Juliana Amaral Medeiros da Silva, ${ }^{1}$ Gerson Siegmund, ${ }^{2}$ Juliana Bredemeier ${ }^{3}$

\begin{abstract}
Introduction: The world's population is often assailed by crises of various orders. Disasters caused by nature and by humans themselves also impact on people's mental health. Psychological crises, such as suicide attempts, represent a growing problem in mental health. When faced with such scenarios, specific strategies of crisis intervention are both appropriate and necessary.

Objective: To conduct a systematic review of the literature dealing with online psychological crisis intervention, describing and discussing their operational design, specific characteristics and applications.

Method: A systematic review of literature indexed on the PubMed, PsycINFO, and SciELO databases identified by searches conducted from January to June of 2014.

Results: The searches identified 17 empirical studies about online crisis interventions which were reviewed. Three crisis contexts emerged: 1) disasters, 2) risk/prevention of suicide, and 3) trauma. Eleven different intervention programs were described and the predominant treatment approach was cognitive behavioral therapy. The results showed that research into online psychological crisis intervention has been conducted in several different countries, especially the Netherlands and Australia, and that the users of these tools benefit from them.

Conclusion: Online crisis interventions have been developed and researched in many countries around the world. In Brazil, there is still a lack of investment and research in this area.
\end{abstract}

Keywords: Crisis intervention, online therapy, crisis management.

\section{Introduction}

It is not a recent phenomenon that the global population is assailed by recurrent crises of a variety of types, demanding structural and particularly

\begin{abstract}
Resumo
Introdução: Frequentemente a população mundial tem sido atingida por crises de diversas ordens. Desastres provocados pela natureza e também pelo homem têm impactado na saúde mental das pessoas. Crises de ordem psicológica, como tentativas de suicídio, têm representado um problema crescente em termos de saúde mental. Frente a esse panorama, estratégias diferenciadas de intervenção em crises são oportunas e necessárias.

Objetivo: Revisar sistematicamente a literatura existente sobre intervenções psicológicas em crises no contexto online, e com isso descrever seu funcionamento e discutir suas particularidades e possibilidades.
\end{abstract}

Método: Realizou-se uma revisão sistemática de literatura, através das bases de dados PubMed, PsyciNFO e SciELO, no período de janeiro a junho de 2014.

Resultados: A presente revisão resultou em 17 estudos empíricos que tratam sobre intervenções em crise no contexto online. Destes, três contextos de crise emergiram: 1) desastres, 2) risco/prevenção de suicídio e 3) trauma. Foram localizados 11 programas de intervenção, nos quais a abordagem de tratamento predominante foi a terapia cognitivo-comportamental. Os resultados mostraram que vários países têm desenvolvido pesquisas sobre intervenções psicológicas em crise no contexto virtual, em especial a Holanda e a Austrália, apresentando benefícios para quem se favorece dessa ferramenta.

Conclusão: Intervenções em crise no contexto online existem e têm sido vastamente desenvolvidas ao redor do mundo. No Brasil, este tema ainda necessita investimento.

Descritores: Intervenções em crise, terapia online, manejo de crises.

emotional readjustment from the people involved. Many such critical events have happened throughout human history: war and atrocities involving loss of human lives, disasters caused by climate changes,

\footnotetext{
${ }^{1}$ Psychologist, private practice, Porto Alegre, RS, Brazil. ${ }^{2}$ PhD candidate in Psychology, Universidade Federal do Rio Grande do Sul (UFRGS), Porto Alegre, RS, Brazil. ${ }^{3}$ PhD in Psychiatry, UFRGS, Porto Alegre, RS, Brazil. Coordinator, School of Psychology, Faculdade de Desenvolvimento do Rio Grande do Sul (FADERGS), Porto Alegre, RS, Brazil.

Financial support: none.

Submitted Jun 14 2014, accepted for publication Aug 22 2014. No conflicts of interest declared concerning the publication of this article.

Suggested citation: da Silva JA, Siegmund G, Bredemeier J. Crisis interventions in online psychological counseling. Trends Psychiatry Psychother. 2015; $37(4)$ :171182. http://dx.doi.org/10.1590/2237-6089-2014-0026
} 
and most recently, increasing rates of violence. As a consequence, people seem to live under a constant threat of imminent crises and emergencies.

Collective critical incidents of all kinds have affected people from different countries, epochs and cultures. The increasing rates of violence seen nowadays are another factor that could account for the rise in crisis events. There are is also another class of crises which, unlike external events, have causes intrinsic to individual people. These crises are related to individual issues, such as changes in personal relationships.

In all of the examples mentioned, whether collective or individual, it is undeniable that there is a high risk of psychological distress and so negative consequences for individuals and society are inevitable. It is therefore necessary that the psychology community takes a stand, designing interventions that can support people in the many different types of emergency situations. The importance of effective approaches that can be made available to as many people as possible is increasingly evident.

\section{Definition of crisis}

The term crisis has its origin in the Greek word krisis, which meant decision and comes from the verb krino, which in turn signified to decide, to separate, to judge. ${ }^{1}$ The expression crisis usually refers to negative life events, such as those termed emergencies: disasters driven by natural causes (earthquakes, volcanic eruptions, droughts, floods, tornadoes, hurricanes, etc.); technological disasters like fires, toxic leaks and explosions ${ }^{2}$; and even situations caused directly by man, such as armed conflicts, terrorist attacks, kidnappings, urban violence, drug dealing, and so on. All of these represent threats to people's physical and emotional health. ${ }^{3}$

In addition to the definitions related to external events, a crisis can also be associated with situations in which there is a threat to an individual person's life, home or property and even to one's wellbeing. ${ }^{3}$ There is an aspect of this type crisis that is intrinsic to the individual concerned, such as losses (or the risk of loss), significant changes in a relationship, being diagnosed with a chronic or terminal disease, suicidal thoughts, etc. The most important characteristic of a psychological crisis is not the event per se, but the arrangement of circumstances and contingencies in which the person finds themselves, and their perceptions about the event and the resources they have to deal with it. As a rule, a crisis occurs when the stress and tension in a person's life exceed his or her capacity to cope with the critical event. ${ }^{4,5}$

However, in psychological terms, a crisis can also be understood as the reaction to a situation that threatens a person's physical and/or mental health and people may exhibit clinical symptoms that are a consequence of the emotional state caused by the crisis and demand psychological assistance and care. ${ }^{3}$ Anxiety and depression are the most common responses presented by people who experience crises. Depending on the seriousness of the trauma, people can experience confusion, disruption on all levels, and impairment in problem solving. ${ }^{4,5}$ In severe cases, there is a chance that the patient will develop trauma-related psychopathologies, such as posttraumatic stress disorder (PTSD) or acute stress disorder (ASD). $4,6,7$

Crises (returning once more to the critical events themselves rather than the reaction to them) are restricted to limited periods of time. They are therefore immediate, transitory and temporary episodes, although some people are under constant exposure to distressing situations. This is probably the case of a portion of the Brazilian population who live in circumstances of social vulnerability and experience violence and insecurity day to day. However, in psychological terms, a single crisis might ultimately cause a person great suffering, staying with him or her for a long time and even becoming part of everyday life. . $^{4}$

It is important to note that for certain authors the term crisis has a positive meaning. For instance, in his Psychosocial Development Theory, Erikson ${ }^{8}$ has posited that everyone should undergo crises throughout their lives, because they are chances to evolve. Erikson assumes that resolution - whether it be positive or negative - of such crises will determine the subject's coping repertoire. Therefore, a crisis can be seen as something that is not exclusively prejudicial, but also as an opportunity to grow.

In the present study, the term crisis is understood to refer both to a critical event that takes place during a limited period of time and to a person's psychological reaction to a critical event. ${ }^{1-3,5}$

\section{Crises as an emergent problem in public healthcare}

According to data from the Pan-American Health Organization (PAHO), ${ }^{2}$ the rates of natural and technological disasters in Brazil and other countries have increased exponentially in recent years. The main causes identified by PAHO are the increase in world population, unregulated urban sprawl and intensification of urbanization and industrialization processes.

It is common for healthcare institutions to focus their crisis support services solely on emergency medical care and so they are often unprepared to provide a wider range of assistance. In emergency situations such as natural disasters, existing services prove outdated and 
become overloaded and are thus unable to properly deal with the occurrences, often resulting in public calamity. ${ }^{3}$

Currently, the World Health Organization (WHO) has a structured program to provide support and aid to countries in situations of crisis, particularly those considered underdeveloped. Generally, they have a wide variety of resources. However, to date, mental health support programs rely exclusively on face-to-face intervention. ${ }^{2}$

The Centre for Research on the Epidemiology of Disasters (CRED) reports that there were 321 disasters around the world in 2008, taking the lives of 235,816 people. These figures represent a total cost of US\$ 181 billion (about $\mathrm{R} \$ 407$ billion) for the global economy. ${ }^{9}$ In Brazil, a total of 376 natural disasters were registered in 2012, causing 93 deaths and affecting the lives of $16,977,614$ people. The disasters registered included droughts, forest fires, landmass movements (mudslides, landslides), floods, hailstorms and tornadoes. ${ }^{10}$

This evidence highlights the importance of developing mental health interventions for crises that can be of use when critical events occur. The criteria for the usefulness of interventions are that they must be brief and inexpensive and must reach as many people as possible. ${ }^{11}$

Concerning crises of a psychological nature, there are alarming data on suicidal crises, compelling many countries to pay extra attention to suicide deaths, including Brazil. As reported by the Brazilian Ministry of Health, in 2011 there were a total of 9,852 deaths by suicide for every 100,000 inhabitants, which equates to an average of 27 deaths per day. ${ }^{12}$ Crisis situations can often result in a person suffering a breakdown, involving feelings of abandonment, incapacity, and exhaustion. People going through crises may also fail to see any solutions, leading them to believe that there is no better way out than death, which is the characteristic of a suicidal crisis. ${ }^{1,13}$

Unfortunately, mental health disorders and psychological distress very often go undetected or are not treated appropriately. The general population could benefit significantly were they to be provided with information on the subject, i.e. how to acknowledge mental disorders/distress, which treatments are available and their effectiveness and where to look for emotional support. It is likely that many people in crisis could be motivated to seek help. If the taboos and social stigma related to suicidal behavior were weakened, a lot of people could be encouraged to seek professional psychological assistance. ${ }^{1}$

\section{Crisis interventions}

There are currently several approaches that are used to provide the theoretical and empirical foundations for face-to-face crisis interventions. The most widely used approach, and one that is evidence-based, is cognitive behavioral therapy (CBT). ${ }^{5}$ Notwithstanding, all of the therapeutic approaches taken to crisis intervention, including $\mathrm{CBT}$, are focused on treatment or prevention of the trauma. ${ }^{7}$

Dattilio \& Freeman have proposed a CBT treatment protocol that could be employed in crisis situations in general. ${ }^{5}$ Initially, the aim is to perform a complete assessment of the patient and his or her situation. The next stage consists of challenging the patient's dysfunctional beliefs, creating options in a cooperative way and, finally, establishing hope. The therapist will explore the patient's strengths for coping with the critical situation and understanding the positive potential of a crisis. By doing this, the therapist will be able to provide a feeling of security and generate in the patient the impulse to take control of his or her life, accomplishing the changes needed to move on. ${ }^{4,5}$ The protocol is divided into five stages: 1) development of the therapeutic relationship and establishment of rapport; 2) initial assessment of the severity of the situation; 3 ) supporting the patient to evaluate and activate his or her strengths and resources; 4) cooperative work between patient and therapist to develop a plan of positive action and 5) testing novel behaviors and thoughts. ${ }^{4,5}$

Forbes et al. ${ }^{14}$ have compiled some recommendations for intervention in recent crises, as follows: 1) psychological aid must be delivered, i.e., continuously monitoring the patient's mental state, assuring emotional support, safety, information and assistance, as well as encouraging active use of social support and self-care strategies; 2) excessively structured strategies, such as psychological debriefing, are not endorsed, but those patients who actually wish to talk about their experience and show the ability to handle the distress should be encouraged to do so; 3 ) pharmacotherapy is not recommended as a preventive strategy after being exposed to a traumatic situation, unless the patient exhibits significant symptoms, such as acute insomnia.

Regarding the different psychotherapeutic approaches to trauma, exposure therapy (ET) has achieved positive results for treatment of both PTSD and ASD. ${ }^{14}$ ET consists of exposing the patient to his or her traumatic memories and/or to situations being avoided in a secure and controlled way. The objective is to reduce levels of anxiety and restore the patient's functioning. Usually, ET includes four main components: psychoeducation, breathing training, imaginal exposure and in vivo exposure. ${ }^{14,15}$

Stress inoculation training (SIT) is another intervention focused on trauma and it basically consists 
of a program of anxiety management. The patient is trained in general techniques of anxiety management, to enable him or her to confront three mechanisms of anxiety: cognitive, behavioral and physiological. After an initial stage of psychoeducation, other elements may be included in SIT: relaxation training, role-playing, covert modeling, guided discovery and the "stop and think" strategy. ${ }^{15}$

When it comes to interventions for suicide risk, there is another range of possibilities, although the literature on this particular topic is scant. ${ }^{13}$ The Brazilian Ministry of Health has published a suicide prevention handbook providing guidance for mental health professionals on how to handle and guide patients in crisis. ${ }^{16}$ Furthermore, effective treatment protocols based on approaches such as CBT and dialectical behavior therapy (DBT) have also been developed. ${ }^{17}$ Initially, DBT proved its efficacy with borderline personality disorder patients, but since it is focused on helping patients to reduce and tolerate stress, it has also shown promise for treating suicide risk in other disorders. ${ }^{18}$

Litz et al. ${ }^{11}$ have stated that the limited abilities of therapists could be a barrier to optimum mental health care when a mass casualty incident occurs. In view of this, low-cost short-term interventions that can reach the largest number of victims ought to be designed. It is therefore reasonable to consider increasing the active role of the patient in therapy while reducing the therapist's role. In turn, the therapist could use the Internet or telephone to provide support to a larger number of people and to ensure adherence to selfmanagement strategies.

\section{Online psychological treatments and their link with crisis interventions}

Online psychological treatments comprise a range of interventions. Some examples are: computerized therapies, which are usually software-based; Internetbased therapies using web tools like audio or video conferencing and forums; and text-based therapies, which are generally conducted by e-mail. ${ }^{19-21}$ One criterion for classification of different modalities is by degree of synchronicity: communication via chat, audio and video are classified as synchronous methods, because contact between therapist and patient is simultaneous. In contrast, e-mail, texting and forums are asynchronous, because messages may be answered at a different time. ${ }^{22}$ Additionally, expressions such as therapist-guided, self-guided or self-administered have been used to denote whether there is any contact between therapist and patient and, if so, to what degree. ${ }^{23}$ There is no consensus on terms or definitions, although some guidelines have been established to determine directions for future research. ${ }^{24}$

The Federal Psychology Council has not yet permitted online psychotherapy to be practiced in Brazil, but it has been accepted as a subject of research. Other types of online treatment are allowed, such as online counseling (up to 20 meetings), the first steps of selection processes, virtual psychological testing, and counseling for patients who are traveling on an occasional basis and/or temporarily unable to attend in person. ${ }^{20,25,26}$

To date, there is only one Brazilian online intervention service for crisis contexts: the Centro de Valorização da Vida (www.cvv.org.br), which provides voluntary support to people facing crises, especially suicidal ideation. The service is primarily provided via telephone (hotlines), but there are other contact options too: Skype and e-mail. However, no studies investigating this service were found. We were only able to locate a passing reference to creation of its e-mail channel in a study by Dockhorn \& Werlang. ${ }^{27}$

Although online therapy is still not allowed for professional practice in Brazil, the likelihood of future applications can be gauged on the basis of data on Internet use in the country. According to data from the Brazilian Institute for Geography and Statistics (IBGE), the proportion of people aged 10 or over who have access to the Internet was $20.9 \%$ (equivalent to 31.9 million people) in 2005 and increased to $46.5 \%$ (77.7 million) in $2011 .{ }^{28}$ In a similar manner, the proportion of people aged 10 or over who had a cellphone for personal use rose from $36.6 \%$ ( 55.7 million people) in 2005 to $69.1 \%$ (115.4 million) in $2011 .{ }^{28}$ In 2005, another survey conducted by IBGE found that $71.7 \%$ of the Brazilian population accessed the Internet for education and learning. ${ }^{29}$

In the United States, several mental health institutes began to realize that mobile applications (popularly known as Apps) could help to solve problems in both the individual and collective spheres, including in crisis situations. These may represent an important way of reaching patients who are familiar with technology, such as adolescents and young adults. ${ }^{30}$

Cuijpers et al. ${ }^{31}$ consider that Internet-based interventions offer many advantages over other kinds of interventions: they could save time and commuting for both patients and therapists and reduce the length of waiting-lists and the stigma related to visiting a psychologist or psychiatrist, among others. Adherence problems in self-guided interventions could be addressed by using audiovisual resources that are attractive to users and tailored to their culture. The scope of online interventions encompasses a large set of people who otherwise would have limited access to psychological 
treatment: patients with severe health issues, mobility restrictions, problems with self-disclosure, and so forth. Nonetheless, there are also disadvantages: Internetbased interventions may not be suitable for patients who dislike technology, who have a very low level of education, or who are unable to understand the nuances of digital communication.

Several studies of online interventions exclude patients in crisis from their samples, especially those in suicidal crises. ${ }^{32,33}$ One pioneering crisis intervention service in Israel has realized that the Internet could be used to help people going through severe emotional distress (including suicidal crises), providing intensive and legitimate support. ${ }^{34}$ Individuals going through suicidal crises often do not seek help because of the fear, shame and stigma associated with the subject. The anonymity of an online environment might facilitate these people to find assistance. ${ }^{35}$ Moreover, people in crisis situation may choose to look for information anonymously, on websites or via software, at any time of day, instead of seeking face-to-face support. ${ }^{36}$

Online interventions can be a useful tool for providing early psychological intervention to people who have recently been exposed to trauma, as is the case in large-scale traumatic events. In such situations, mental health care services might be impaired or even unavailable, for logistical and economic reasons. Additionally, as mentioned above, in many situations the local teams are not trained or prepared for this kind of care. It is worth considering that in mass casualty incidents there is a narrow window of time to do anything. Therefore the Internet can be an effective method for reaching victims as soon as possible. ${ }^{37}$

Crises are a real problem that can lead to functional impairment for individuals and economic losses for society. Crisis intervention programs do exist, but their reach is limited. Particularly in Brazil, this is a topic that still lacks investment. Online interventions may be an effective and inexpensive option for providing psychological assistance in crisis situations, as well as for improving access to treatment for those who are unable to attend traditional treatments. Online crisis intervention could also provide an option for preventing severe psychological harm, thereby reducing the impact of crises on society. To our knowledge, there are no studies about this subject in Brazil.

The aim of the present study is to systematically review psychological crisis interventions that have been provided through online systems. The objective is to describe these interventions' procedures and operational designs and to discuss their specific characteristics and applications.

\section{Method}

\section{Search method}

We conducted a review of the literature on online psychological treatments for crises. Drawing on the concept of crisis, $2,3,5$ the descriptors chosen for the search were: suicide prevention, psychological first aid, crisis intervention, crisis management, disaster mental health assistance, and crisis coping. The corresponding terms in Portuguese were also used. These descriptors were combined with expressions specifying the treatment delivery method: online, Internet and computerized, and, once more, the corresponding terms in Portuguese. These searches were run on the PubMed, PsyciNFO and SciElo databases from January to June of 2014. As a supplementary strategy, the reference lists of the articles selected were also checked for additional studies that were related to the subject, but that had not appeared in the initial searches.

\section{Inclusion criteria}

Articles were included in the review if they met the following criteria : a) reporting any online crisis intervention, even if concurrent with other interventions; b) full text of the article written in Portuguese, English or Spanish; c) based on empirical data; and d) published between 2000 and 2014. If two different studies reported on the same intervention, they were both included as long as they contained complementary data.

\section{Exclusion criteria}

Articles were excluded if they: a) were not based on empirical data; b) described online interventions not focused on crises; c) were related to non-online distance treatment methods (e.g. via telephone); d) the full text was not available; or e) were repeats or duplicates.

\section{Procedures and data analysis}

First, the abstracts of all articles were read, both from the databases search and from the additional sources. The inclusion and exclusion criteria were then applied and the full texts of eligible articles were read. Next, the articles were arranged in tables and categories for data analysis. Figure 1 illustrates the steps of the search strategy. The results of the review are presented below. 


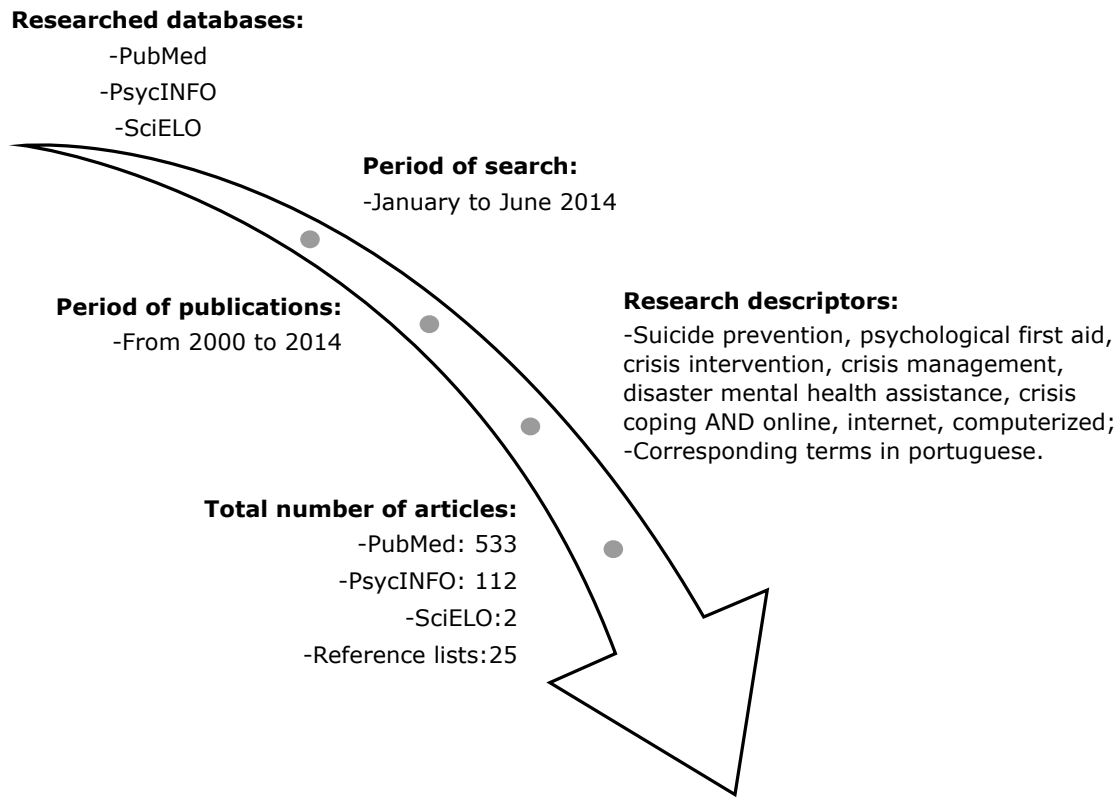

Number of articles included in the review:

17

Figure 1 - Flowchart illustrating systematic review search strategy.

\section{Results and discussion}

The search strategy identified 17 empirical studies which were included in the systematic review. Eleven of these were randomized clinical trials or pilots for randomized clinical trials, $^{32,33,35,37-44}$ three of them were reports of experience ${ }^{9,11,34}$ and the remaining three fell into other categories. ${ }^{45-47}$ Several different crisis contexts were identified and so the articles were allocated to three categories to provide a framework for organizing the results, as follows (Table 1): interventions in disasters, interventions in suicide risk and suicide prevention, and interventions in traumas.

Eleven models of online crisis intervention were found (Table 2). These programs are still ongoing, since the websites were tested in randomized clinical trials and

Table 1 - Article categorization by crisis context and method

\begin{tabular}{|c|c|c|}
\hline $\begin{array}{l}\text { Disasters } \\
\text { (1 article) }\end{array}$ & $\begin{array}{c}\text { Suicide risk/ } \\
\text { prevention } \\
\text { (6 articles) }\end{array}$ & $\begin{array}{c}\text { Trauma } \\
\text { (10 articles) }\end{array}$ \\
\hline \multirow[t]{10}{*}{ Bae et al. ${ }^{9}$} & van Spijker et al. ${ }^{35}$ & Hirai \& Clum $^{46}$ \\
\hline & van Spijker et al. ${ }^{32}$ & Lange et al. ${ }^{38}$ \\
\hline & van Spijker et al. ${ }^{43}$ & $\begin{array}{l}\text { Knaevelsrud \& } \\
\text { Maercker }^{47}\end{array}$ \\
\hline & Barak $^{34}$ & Wagner et al. ${ }^{44}$ \\
\hline & Gilat \& Shahar ${ }^{45}$ & Litz et al. ${ }^{39}$ \\
\hline & Christensen et al. ${ }^{42}$ & Litz et al. ${ }^{11}$ \\
\hline & & Mouthaan et al. ${ }^{37}$ \\
\hline & & Mouthaan et al. ${ }^{40}$ \\
\hline & & Cox et al. ${ }^{41}$ \\
\hline & & Robinson et al. ${ }^{33}$ \\
\hline
\end{tabular}

judged worthy of being kept active. Neither the results of these studies nor their effect sizes will be presented here, rather this study will focus on describing the designs of the various different interventions they investigated.

The Netherlands was the country in which the largest number of studies were conducted $(n=6)$, followed by the United States $(n=3)$ and Australia $(n=3)$, as can be seen in Table 3. The most recent studies are from 2013 and 2014 and were conducted in the Netherlands ${ }^{32,40}$ and Australia. ${ }^{33,42}$ All interventions employed native languages, but in several studies the researchers declared an interest in expanding the intervention platforms to other languages, aiming to expand access to include users from other locations. ${ }^{9,34,38,45}$ Studies by Wagner et al. ${ }^{44}$ and Knaevelsrud \& Maercker ${ }^{47}$ investigate interventions resulting from such efforts after a Dutch intervention (Interapy) was translated into Arabic and German respectively. This illustrates a characteristic unique to online treatments, because whereas traditional interventions have to concentrate on a specific place, online interventions can overcome physical limitations and focus their strategies on broadening reach of treatments and access to them.

\section{Crisis intervention based on online environments}

The majority of the interventions reviewed focused on treating patients after onset of crisis (psychologically speaking). A small number of studies $^{9,37,40,41}$ described interventions that focused on 
Table 2 - Descriptions of online crisis interventions

\begin{tabular}{|c|c|c|c|}
\hline Author/year & Design of the service/intervention & $\begin{array}{l}\text { Population/ } \\
\text { audience }\end{array}$ & Intervention name/website \\
\hline Barak $^{34}$ & $\begin{array}{c}\text { Consists of: 1) informative sessions (articles, hotline } \\
\text { links, related websites), 2) SC individual communication } \\
\text { (LivePerson chat software or ICQ instant messaging } \\
\text { software), 3) AS individual communication (e-mail), 4) } \\
\text { AS group communication (online forums in Tapuz portal), } \\
\text { divided into young, adults, enlisted soldiers, and creative } \\
\text { support. }\end{array}$ & A/Ad & Sahar/http://www.sahar.org.il \\
\hline Gilat \& Shahar ${ }^{45}$ & $\begin{array}{l}\text { Individual SC counseling through ICQ and AS support } \\
\text { group. }\end{array}$ & $\mathrm{A} / \mathrm{Ad}$ & $\begin{array}{l}\text { ERAN - Israeli Association for } \\
\text { Emotional First Aid }\end{array}$ \\
\hline $\begin{array}{l}\text { van Spijker et al. }{ }^{32} \\
\text { van Spijker et al. }{ }^{43} \\
\text { van Spijker et al. }{ }^{35}\end{array}$ & $\begin{array}{c}\text { Six modules, focused on: } 1 \text { ) recurrent nature of SDs, 2) } \\
\text { regulation of intense emotions, 3) detection of automatic } \\
\text { thoughts, 4) thought patterns, 5) challenging thoughts, } \\
\text { and 6) relapse prevention. Each module comprises: } 1 \text { ) } \\
\text { theoretical session, 2) weekly tasks (cognitive and/or } \\
\text { behavioral), 3) fundamental exercises, and 4) optional } \\
\text { exercises. }\end{array}$ & A & 113 Online/www.1130nline.nl \\
\hline Hirai \& Clum $^{46}$ & $\begin{array}{l}\text { Eight weeks of intervention comprising: 1) information, } \\
\text { 2) relaxation training (including breathing techniques, } \\
\text { PMR and IIR), 3) cognitive restructuring, and 4) exposure } \\
\text { modules (written). }\end{array}$ & A & SHTC \\
\hline Lange et al. ${ }^{38}$ & $\begin{array}{l}\text { Five weeks of intervention (written) divided into three } \\
\text { stages: } 1 \text { ) self-confrontation ( } P \text { about ET and beginning of } \\
\text { exposure), } 2 \text { ) cognitive reappraisal ( } P \text { about the cognitive } \\
\text { model, "letter of support to a friend" task), and } 3 \text { ) sharing } \\
\text { and farewell ritual ( } P \text { about the positive effects of sharing } \\
\text { the experience, and "letter of farewell to trauma" task). }\end{array}$ & A & $\begin{array}{l}\text { Interapy (Netherlands)/www. } \\
\text { interapy.nl }\end{array}$ \\
\hline $\begin{array}{l}\text { Knaevelsrud \& } \\
\text { Maercker }\end{array}$ & $\begin{array}{l}\text { The intervention is identical to the study by Lange et al., } \\
\text { but translated into German. }\end{array}$ & A & Interapy (Germany)/www.interapy.nl \\
\hline Wagner et al. ${ }^{44}$ & $\begin{array}{c}\text { The intervention is similar to the study by Lange et al. }{ }^{38} \\
\text { but was translated and tailored to the Iraqi culture. The } \\
\text { Ilajnafsy website, which means psychological support, } \\
\text { provides online assessment and information about PTSD } \\
\text { and about the treatment program. }\end{array}$ & A & Interapy (Iraq)/www.ilajnafsy.org \\
\hline $\begin{array}{l}\text { Litz et al. }{ }^{39} \\
\text { Litz et al. }{ }^{11}\end{array}$ & $\begin{array}{l}\text { A platform containing information about PTSD, } \\
\text { strategies of anger control and sleep hygiene. Eight } \\
\text { weeks of intervention consisting of: } 1 \text { ) FtF interview } \\
\text { for } \mathrm{P} \text {, generation of an early hierarchy of triggers, early } \\
\text { training in SMS and early counseling about cognitive } \\
\text { resignification, 2) self-monitoring of triggers, } 3 \text { ) generation } \\
\text { of an expanded hierarchy of triggers, 4) training in SMS } \\
\text { (DR, PMR and DB), 5) graded exposure to the hierarchy } \\
\text { items, 6) seven sessions of narrative writing about the } \\
\text { traumatic situation (exposure), and 7) evaluation of } \\
\text { progress, relapse prevention and design of a plan for } \\
\text { future challenges. }\end{array}$ & USA DDM & $\begin{array}{l}\text { DE-STRESS - DElivery of Self- } \\
\text { TRaining and Education for Stressful } \\
\text { Situations/www.de-stress.org \& SIT } \\
\text { - Stress Inoculation Training }\end{array}$ \\
\hline $\begin{array}{l}\text { Mouthaan et al. }{ }^{40} \\
\text { Mouthaan et al. }{ }^{37}\end{array}$ & $\begin{array}{l}\text { Preventive intervention. Consists of six steps including } \mathrm{P} \text {, } \\
\text { in-vivo exposure, SMS, and social support: } 1 \text { ) introduction } \\
\text { and log-in (program aims and basic instructions), 2) } \\
\text { assessment of anxiety and arousal levels, 3) trauma and } \\
\text { experiences (users watch two videos: one with a trauma } \\
\text { specialist explaining the procedures, and one with three } \\
\text { patients sharing their experiences after the trauma). At } \\
\text { the end of the third step there is a summary with five tips } \\
\text { for handling the usual physical and psychological reactions } \\
\text { post-trauma, then 4) two audio clips with instructions } \\
\text { about SMS (PMR and SPT), 5) another assessment of } \\
\text { anxiety and arousal, and } 6 \text { ) program assessment. Patients } \\
\text { get a link to access a web forum where they can share } \\
\text { experiences and find mutual support. }\end{array}$ & A & Trauma TIPS/www.traumatips.nl \\
\hline Bae et al. ${ }^{9}$ & $\begin{array}{c}\text { An educational website about disasters, emphasizing } \\
\text { the relevance of prevention. It works as an online } \\
\text { psychological intervention. }\end{array}$ & GP & $\begin{array}{l}\text { National Emergency Management } \\
\text { Agency (NEMA) - Jaenan Pihaeja } \\
\text { Simlijiwon Center/www.dmhs.go.kr }\end{array}$ \\
\hline
\end{tabular}




\begin{tabular}{|c|c|c|c|}
\hline Cox et al. ${ }^{41}$ & $\begin{array}{l}\text { Friendly and accessible website approach for children. It } \\
\text { begins with a page of general instructions. Next, the child } \\
\text { clicks on the link that matches his or her age: children ( } \leq \\
10 \text { years of age) or adolescents }(\geq 11) \text {. The next screen } \\
\text { shows icons with session titles: } 1 \text { ) feelings, } 2 \text { ) detecting } \\
\text { strengths, } 3 \text { ) growing and learning, } 4 \text { ) heroes, 5) solving } \\
\text { problems, 6) reaching out, } 7 \text { ) talk to yourself, and } 8 \text { ) } \\
\text { help (provides a hotline number and other strategies the } \\
\text { child/teen can use). Examples are provided to encourage } \\
\text { learning and practice of SMS, confrontation, PST and } \\
\text { reflection about the situation (learning and growing } \\
\text { from the challenge). There is also a link for parents with } \\
\text { information regarding their children's possible symptoms } \\
\text { after a trauma. }\end{array}$ & $\mathrm{C}$ & $\begin{array}{l}\text { "So you have been in an accident"/ } \\
\text { http://kidsaccident.psy.uq.edu.au }\end{array}$ \\
\hline Robinson et al. ${ }^{33}$ & $\begin{array}{l}\text { The website has an adult "host" character who delivers } \\
\text { the therapy verbally and a series of videos in which young } \\
\text { actors tell a different story every week. Consists of eight } \\
\text { modules: 1) definition of engagement in therapy and } \\
\text { agenda setting, 2) identifying emotions and tolerating } \\
\text { anguish, 3) detecting automatic negative thoughts, 4) } \\
\text { behavioral activation - looking for help, 5) scheduling of } \\
\text { activities (including SMS), 6) PST focusing particularly on } \\
\text { managing suicidal ideation, 7) identifying and challenging } \\
\text { problematic thought, and 8) cognitive restructuring. }\end{array}$ & Ad & Reframe IT \\
\hline Christensen et al. ${ }^{42}$ & $\begin{array}{c}\text { The intervention consists of internet-based P (one week) } \\
\text { delivered through BluePages (an educational website that } \\
\text { provides information about evidence-based treatments } \\
\text { for depression), combined with web-based CBT (two to } \\
\text { four weeks) provided by MoodGym (a web application that } \\
\text { delivers CBT in five modules). }\end{array}$ & $A$ & $\begin{array}{c}\text { BluePages \& MoodGYM/http:// } \\
\text { bluepages.anu.edu.au \& http:// } \\
\text { moodgym.anu.edu.au }\end{array}$ \\
\hline
\end{tabular}

Table 3 - Number of studies by country

\begin{tabular}{lc}
\hline Country & $\mathbf{n}$ \\
\hline Australia & 3 \\
Germany & 1 \\
Iraq & 1 \\
Israel & 2 \\
The Netherlands & 6 \\
South Korea & 1 \\
United States & 3 \\
Total & 17 \\
\hline
\end{tabular}

prevention of severe symptoms, such as development of PTSD. In one of these studies, related to preventing disorders in people who had been exposed to trauma, 40 the authors mentioned encountering barriers to patients' adherence to treatment. They noticed that in some cases, during the critical phase of exposure to the traumatic situation, victims turned to their loved ones and support networks to seek help, rather than to health professionals. However, this observation needs further investigation.

The main therapeutic approach in the studies was CBT, either as exclusive therapy or combined with other treatments (Table 4), which is in line with current recommendations in the literature regarding the applicability and efficacy of this approach. ${ }^{4,5,7}$ One of the
Table 4 - Clinical intervention approaches

\begin{tabular}{lc}
\hline Approach & $\begin{array}{c}\text { Number } \\
\text { of articles }\end{array}$ \\
\hline Cognitive behavioral therapy & 9 \\
Cognitive behavioral therapy + exposure therapy & 1 \\
Cognitive behavioral therapy + stress inoculation & 1 \\
training & 1 \\
Psychoeducation + debriefing and defusing & 5 \\
Information not provided & 17 \\
Total & \\
\hline
\end{tabular}

studies $^{41}$ underlined the need to explore adaptation of CBT to the online environment in detail, i.e., whether any pertinent adaptations could improve the intervention.

Some authors consider that self-guided CBT is a potential solution for a variety of needs, in particular because CBT is a low-cost treatment, because it can reduce the stigma related to seeking for help and because it is effective for treatment of PTSD, especially in the contexts of war, disasters and the emergency services. This approach should be considered and evaluated in depth. ${ }^{37,39}$

With regard to the practice of psychoeducation, this was included as a supplementary treatment in almost all interventions $(n=16)$. Although not all articles explicitly used the word psychoeducation, similar strategies were present in almost all studies. For example, providing 
general information, information about psychological disorders or about how to manage stress, explaining psychological functioning in crisis situations, and so forth. This data illustrates a major characteristic of CBT approaches and also of online interventions, specifically that the objective of psychological treatments is more and more to train the patients themselves to deal with their problems, widening the reach of a single therapist to provide care to a larger number of patients, with lower costs for both sides, which is very relevant in the context of crises.

With regard to target populations, the majority of interventions ( $n=10$ ) were aimed at adults (18 years or over). Just one study was designed for children. ${ }^{41}$ Although this is the only such study, it raises the possibility of a unique type of intervention, since it employs audiovisual resources to offer an attractive environment to children. This intervention suggests that it is possible to act preventatively and target a wide range of groups of people, underscoring the versatility of online interventions.

Likewise, just one study ${ }^{33}$ was aimed exclusively at adolescents (up to 18 years old), although another two articles included adolescents in their samples. ${ }^{34,45}$ As highlighted in the literature, members of this particular section of the population have a high degree of familiarity with technology and the nuances of digital communication, often choosing this environment to express their feelings. ${ }^{28,30}$ It is clear that when it comes to crises, possibilities for providing support for children and adolescents are still underexplored.

Only one intervention dealt directly with disasters, although other studies mentioned people hit by disasters or catastrophes. A study by Bae et al. ${ }^{9}$ explains that their intervention was designed on the basis of research with the population of South Korea, which is constantly hit by disasters and where there is a clear need for specific interventions. This study has a multidisciplinary approach and the whole team must undertake rigorous specific training about how to act in disaster situations, both in conventional and online contexts. Even though the literature emphasizes the importance of creating strategies that enable mental health services to reach the victims of disasters, ${ }^{11}$ it remains to be answered how this would be achieved in regions where, in addition to many other problems, telecommunications may be inoperative. The need for more studies in this area is evident. Notwithstanding, a consideration made by Wagner et al. ${ }^{44}$ is noteworthy, since they explain that native psychiatrists and psychologists who are geographically separated from their patients may still be able to provide a treatment option to post-conflict or post-disaster areas, where there is an urgent need for psychological support, but where face-to-face treatment may not be available.

Several studies emphasize the point that online interventions can be inexpensive when compared to traditional interventions, ${ }^{9,37-39}$ which is one of the main issues to be considered when discussing whether online interventions should be allowed in Brazil by the Federal Council of Psychology. In a pioneering study, van Spijker et al. ${ }^{43}$ analyzed the cost-effectiveness of an online treatment for suicide prevention, pointing out that economic assessments of suicide interventions are almost nonexistent. This has been attributed to a lack of substantial evidence regarding the efficacy of such programs and so it is reasonable to suggest that this aspect merits further investigation.

\section{Specific characteristics of the online in- tervention technologies}

Most studies ( $n=13$ ) mentioned the possibility of anonymity and either permitted it or explained the reasons why anonymity was not allowed (Table 5). Discussions of online treatments often stress anonymity. For example, a study by van Spijker et al. ${ }^{35}$ explained that anonymity was considered impracticable because of ethical aspects of the context of the intervention, in which the patient was at risk of suicide, had to be taken into account. However, this position contrasted with the stance taken by other authors, ${ }^{34,42,44,45}$ who considered that it was worth taking the opportunity of providing psychological support, even anonymously, even if this involved accepting some risk of the patient committing suicide. In return, the intervention is available and accessible to a lot of people. Some studies also discussed anonymity of the therapists/professionals, such as studies by Barak ${ }^{34}$ and Gilat \& Shahar. ${ }^{45}$ Barak $^{34}$ points out that anonymity can be both an advantage and a disadvantage, since therapists are subject to shammers willing to disturb their work. Other weaknesses highlighted are related to problems with technology which, even more than in other types of online interventions, cannot happen in a crisis intervention. ${ }^{34,38}$

Wagner et al. ${ }^{44}$ also note the importance of anonymity, but mainly stress the chance of delivering the treatment in a private and reserved way, even when the therapist is geographically distant. These authors consider that victims of trauma, such as those who live in conflict areas like Iraq, may benefit from this kind of intervention, since it reduces barriers such as moral and religion values related to the trauma and the stigma of therapy, which can make it hard for a patient to open up in person. 
Table 5 - Specific characteristics of technologies used in crisis interventions

\begin{tabular}{lc}
\hline Characteristics & Number of studies \\
\hline Synchronicity & 15 \\
Asynchronous & 0 \\
Synchronous & 2 \\
Asynchronous + synchronous & \\
Anonymity & 4 \\
Yes & 9 \\
No & 4 \\
Information not provided & \\
Guidance & 9 \\
Self-guided & 3 \\
Self-guided* & 0 \\
Therapist guided & 5 \\
Self-guided + therapist guided & 17 \\
Number of articles &
\end{tabular}

* With therapist contact when needed.

With regard to who guides the therapy, all of the studies in this review included some degree of self-management from patients, either total or partial (Table 5). In the interventions described, therapist contact took the form of feedback on task completion, $33,38,39,47$ encouragment, ${ }^{38,47}$ checking on patients' motivation, ${ }^{32,38,47}$ psychoeducation, ${ }^{32,33,38,39,47}$ application of techniques, $33,38,39,47$ and face-to-face assessments before intervention. ${ }^{11,33,39}$ However, in all cases the patient takes the major role in conducting the therapy.

Concerning the degree of synchronicity, none of the interventions were completely synchronous and asynchronous approaches were in the majority. These took the form of e-mail counseling, messages via websites, conducting written activities, and others. Two interventions involved mixed intervention (both synchronous and asynchronous interaction). ${ }^{34,45}$ In these cases, the synchronous elements involved online chat and forums. Almost all of the interventions reviewed included a website that worked as an intervention center, thereby enabling some degree of synchronicity, since they could be accessed 24 hours a day.

\section{Interventions}

With regard to the interventions offered, four studies $^{34,37,40,45}$ involved a group treatment option, either via a forum or online chat. The others offered individual treatment only ( $n=12)$ and one study did not provide this information. There are claims in the literature that internet groups favor mutual understanding and improve feelings of being welcome. A virtual environment can favor self-disclosure, as well as allowing greater disinhibition of expression of emotion. These strengths become specially relevant in crisis situations, in which people need to be supported in their suffering. ${ }^{31,45}$ In one intervention ${ }^{34}$ a specific group was created for people to share their suffering through artistic expression, i.e. via music, poetry, and art in general. This is a further illustration of the flexibility of online interventions. Groups can be moderated by the users themselves, but they are ideally moderated by an expert, so the therapist can intervene in the event of a more severe situation. ${ }^{45}$

Still with relation to the interventions, Lange et al. ${ }^{38}$ highlight that one advantage of the Interapy approach (Table 2), compared to a face-to-face treatment, is that the therapist does not have to give the patient an immediate answer, which allows some time for thinking and for formulation of the most appropriate feedback. In some interventions, the option of face-to-face treatment was included, either when a demand was identified 37,40 or as a constant part of the program. ${ }^{9,11,33,34,39}$ This is the case of the Zahar Project, ${ }^{34}$ in which, if a situation of imminent risk of suicide was detected, a specific team was activated to provide specialized face-to-face support. This kind of approach illustrates the point that online treatments are not being developed in order to replace or reject the traditional work of psychologists. Rather, the aim is to provide new methods of access to patients, offering help in ways that are attuned to contemporary needs. ${ }^{43}$

Some authors argue that Internet interventions should be seen as a first step into the mental healthcare system and not as an exclusive treatment. Hence, the patient has a first option, and if this is not sufficient or appropriate, the next step would be face-to-face treatment. The mental healthcare system in the Netherlands, where online psychological treatments are allowed, works this way. ${ }^{38,39}$

It was noted that interventions were conducted by several different categories of professionals, who may or not have specific education and training. These therapists can be divided into the following categories: volunteers $(n=2)$, psychologists and psychiatrists ( $n$ $=4)$, therapists in general $(n=5)$, psychologists ( $n=$ $4)$, and multidisciplinary teams $(n=1)$. Generally, those providing care, should have personal characteristics that meet the demands, like empathy and a great ability to listen, regardless of their specific qualifications.

\section{Conclusions}

Online psychological crisis interventions do exist and they have been widely developed in many countries around the world. Countries such as the Netherlands 
and Australia are emerging at the forefront of this kind of intervention. In Brazil, practice and research in this area are still incipient and therefore in need of investment. Further studies of online crisis interventions are necessary and could provide a foundation for approval of online psychotherapies by the Brazilian Federal Council of Psychology, since this practice is not yet permitted in Brazil.

Online interventions can provide instant, effective and low-cost access to treatments that is not limited to business hours, which is extremely important because crises do not choose time or place. In the absence of conventional and well-accepted methods, technologybased approaches may be able to provide solutions to reduce people's suffering. It is worth underlining once more that online interventions are not intended to replace face-to-face treatment, but to offer alternatives that are adapted to the varying different human needs, working both as early strategies and as complementary approaches.

It appears that there are appropriate conditions for the use of online interventions in crises. The articles reviewed have provided evidence in favor of an option that had been previously discarded, since patients in crisis were typically excluded from online therapy studies, maybe because there were no methodological guidelines on how to proceed. It also turns out to be significant that future studies should explore the ethical questions involved in this kind of intervention.

One article related to the use of Apps in crisis interventions was not included in the review because of its methodology. This article mentioned several applications that have already been released to the public, but provided no evidence from research. This situation illustrates the need to continue investing in new technologies for psychology, but also to test their effectiveness, providing consistent and reliable data about this class of intervention. ${ }^{30}$

To our knowledge, this is the first review in Brazil to systematically address crisis interventions delivered online. Consequently, a great deal of information, such as the results of the interventions reported by the articles, was not focused on here, and therefore is still in need of attention. Future studies should explore the results in terms of the cost-effectiveness of these interventions. The present study adds to knowledge on online psychological work in general and provides preliminary information about emerging interventions.

\section{References}

1. Botega NJ, Silveira IU, Mauro ML. Telefonemas na crise: percursos e desafios na prevenção do suicídio. Rio de Janeiro: ABP; 2010.
2. Pan American Health Organization (PAHO) [Internet]. 2014 [cited 2014 Jun12]. http://www.paho.org/bra/index.php?option=com content\&view $=$ article\&id $=578 \&$ Itemid $=1$

3. Sá SD, Werlang BS, Paranhos ME. Intervenção em crise. Rev Bras Ter Cogn. 2008;4:73-80.

4. Fusco GM. Crisis intervention. In: Felgoise S, Nezu AM, Nezu CM, Reinecke MA, editors. Encyclopedia of cognitive behavior therapy. New York: Springer; 2005. p. 146-50.

5. Dattilio MF, Freeman A. Estratégias cognitivo-comportamentais de intervenções em crise. $2^{a}$ ed. Porto Alegre: Artmed; 2004.

6. Associação Americana de Psiquiatria. Manual Diagnóstico e Estatístico de Transtornos Mentais, 4a edição (DSM-IV). Porto Alegre: Artes Médicas; 2002.

7. Romani-Sponchiado $A$, da Silva $C R$, Kristensen $\mathrm{CH}$. Psicoterapia cognitivo-comportamental para o transtorno de estresse agudo: uma revisão sistemática. Rev Bras Ter Comport Cogn. 2013;15:64-74.

8. Erikson EH. Infância e sociedade. $2^{a}$ ed. Rio de Janeiro: Zahar; 1987.

9. Bae J, Kim KY, Panuncio RL, Choi N, Im SB. Inauguration of the first Psychological Support Center for disaster victims in Korea. Nurs Health Sci. 2009;11:351-6.

10. Brasil, Ministério da Integração Nacional, Secretaria Nacional de Defesa Civil, Centro Nacional de Gerenciamento de Riscos e Desastres. Anuário brasileiro de desastres naturais: 2011. Brasília: CENAD; 2012. http://www.integracao.gov.br/c/ document library/get file?uuid=e3cab906-c3fb-49fa-945d649626acf790\&groupId $=185960$

11. Litz BT, Williams L, Wang J, Bryant R, Engel CC. A therapistassisted Internet self-help program for traumatic stress. Prof Psychol Res Pr. 2004;35:628-34.

12. Brasil, Ministério de Saúde. Estatísticas vitais, mortalidade. [Internet]. 2014. [cited 01 Jun 2014]. http://www2.datasus.gov. br/DATASUS

13. Seminotti $E P$, Paranhos $M E$, Thiers VO. Intervenção em crise e suicídio: análise de artigos indexados [Internet]. 2006 Aug 28 [cited 2015 Oct 27]. http://www.psicologia.pt/artigos/textos/ A0297.pdf

14. Forbes D, Creamer MC, Phelps AJ, Couineau A, Cooper JA, Bryant $\mathrm{RA}$, et al. Treating adults with acute stress disorder and posttraumatic stress disorder in general practice: a clinical update. Med J Aust. 2007;187:120-3.

15. Rauch SA, Foa EB. PTSD. In: Felgoise S, Nezu AM, Nezu CM, Reinecke MA, editors. Encyclopedia of cognitive behavior therapy. New York: Springer; 2005. p. 304-7.

16. Brasil, Ministério de Saúde. Prevenção do suicídio: manual dirigido a profissionais de equipes de saúde mental. Estratégia Nacional de Prevenção do Suicídio. Brasília: Ministério da Saúde; 2006.

17. Joiner TE, Williams MF. Suicide-adult. In: Felgoise S, Nezu AM, Nezu CM, Reinecke MA. Encyclopedia of cognitive behavior therapy. New York: Springer; 2005. p. 391-4.

18. Sudak DM. Combinando terapia cognitivo-comportamental e medicamentos: uma abordagem baseada em evidências. Porto Alegre: Artmed; 2012.

19. Donnamaria CP. Experiências de atendimento psicológico grupal via internet: uma perspectiva psicanalítica [tese]. Campinas: Pontifícia Universidade Católica de Campinas; 2013.

20. Marot RS, Ferreira MC. Atitudes sobre a aprovação da psicoterapia online na perspectiva da teoria da ação racional. Interam J Psychol. 2008;42:317-24.

21. Prado OZ. Terapia via internet e relação terapêutica [dissertação]. São Paulo: Instituto de Psicologia da Universidade de São Paulo; 2003.

22. Prado $\mathrm{OZ}$, Meyer SB. Avaliação da relação terapêutica na terapia assíncrona via internet. Psicol Estud. 2006;11:247-57.

23. Barak A, Klein B, Proudfoot JG. Defining Internet-supported therapeutic interventions. Ann Behav Med. 2009;38:4-17.

24. Proudfoot J, Klein B, Barak A, Carlbring P, Cuijpers $P$, Lange A, et al. Establishing guidelines for executing and reporting Internet intervention research. Cogn Behav Ther. 2011;40:82-97.

25. Vicente DO. Psicologia online, uma nova modalidade. [Internet]. 2012 [cited 12 Jun 2014]. http://www.psicologia.pt/artigos/ver_ artigo.php?codigo $=\mathrm{A} 0632$

26. Brasil, Conselho Federal de Psicologia. Resolução CFP no 011/2012, de 15 de julho de 2012. http://www.crpsp.org.br/ portal/orientacao/resolucoes_cfp/fr_cfp_011-12.aspx

27. Dockhorn CN, Werlang BS. Programa CVV: prevenção do suicídio no contexto das hotlines e do voluntariado. Rev Textos Contextos (Porto Alegre). 2008; 7:183-98.

28. Instituto Brasileiro de Geografia e Estatística (IBGE). Pesquisa 
Nacional por Amostra de Domicílios (PNAD), 2011. Acesso à Internet e posse de telefone móvel celular para uso pessoal [Internet]. [cited 2015 Oct 27] Rio de Janeiro: IBGE; 2013. http://www.ibge. gov.br/home/estatistica/populacao/acessoainternet2011 /

29. IBGE. Pesquisa Nacional por Amostra de Domicilios (PNAD), 2005. Acesso à Internet e posse de telefone móvel celular para uso pessoal. Rio de Janeiro: IBGE; 2007.

30. Aguirre RT, McCoy MK, Roan M. Development guidelines from a study of suicide prevention mobile applications (Apps). J Technol Hum Serv. 2013;31:269-93.

31. Cuijpers P, van Straten A, Andersson G. Internet-administered cognitive behavior therapy for health problems: a systematic review. J Behav Med. 2008;31:169-77.

32. van Spijker BA, van Straten A, Kerkhof AJ. Effectiveness of online self-help for suicidal thoughts: results of a randomised controlled trial. PLoS One. 2014;9:e90118.

33. Robinson J, Hetrick S, Cox G, Bendall S, Yuen HP, Yung A, et al. Can an Internet-based intervention reduce suicidal ideation, depression and hopelessness among secondary school students: results from a pilot study. Early Interv Psychiatry. 2014 Mar 31. [Epub ahead of print]

34. Barak A. Emotional support and suicide prevention through the Internet: a field project report. Comput Human Behav. 2007;23:971-84.

35. van Spijker BA, van Straten A, Kerkhof AJ. The effectiveness of a web-based self-help intervention to reduce suicidal thoughts: a randomized controlled trial. Trials. 2010;11:25.

36. Luxton DD, June JD, Kinn JT. Technology-based suicide prevention: current applications and future directions. Telemed J E Health. 2011;17:50-4

37. Mouthaan J, Sijbrandij M, Reitsma JB, Gersons BP, Olff M. Internet-based prevention of posttraumatic stress symptoms in injured trauma patients: design of a randomized controlled trial. Eur J Psychotraumatol. 2011;2. Epub 2011 Nov 4.

38. Lange A, Rietdijk D, Hudcovicova $M$, van de Ven JP, Schrieken $B$, Emmelkamp PM. Interapy: a controlled randomized trial of the standardized treatment of posttraumatic stress through the Internet. J Consult Clin Psychol. 2003;71:901-9.
39. Litz BT, Engel CC, Bryant RA, Papa A. A randomized, controlled proof-of-concept trial of an Internet-based, therapist-assisted self-management treatment for posttraumatic stress disorder. Am J Psychiatry. 2007;164:1676-83.

40. Mouthaan J, Sijbrandij M, de Vries GJ, Reitsma JB, van de Schoot $R$, Goslings JC, et al. Internet-based early intervention to prevent posttraumatic stress disorder in injury patients: randomized controlled trial. J Med Internet Res. 2013;15:e165.

41. Cox CM, Kenardy JA, Hendrikz JK. A randomized controlled trial of a web-based early intervention for children and their parents following unintentional injury. J Pediatr Psychol. 2010;35:581-92.

42. Christensen $H$, Farrer $L$, Batterham PJ, Mackinnon A, Griffiths $\mathrm{KM}$, Donker T. The effect of a web-based depression intervention on suicide ideation: secondary outcome from a randomised controlled trial in a helpline. BMJ Open. 2013;3(6). pii: e002886.

43. van Spijker BA, Majo MC, Smit F, van Straten A, Kerkhof AJ. Reducing suicidal ideation: cost-effectiveness analysis of a randomized controlled trial of unguided web-based self-help. J Med Internet Res. 2012;14:e141.

44. Wagner B, Schulz W, Knaevelsrud C. Efficacy of an Internet-based intervention for posttraumatic stress disorder in Iraq: a pilot study. Psychiatry Res. 2012;195:85-8.

45. Gilat I, Shahar G. Emotional first aid for a suicide crisis: comparison between Telephonic hotline and Internet. Psychiatry. 2007;70:12-8.

46. Hirai M, Clum GA. An Internet-based self-change program for traumatic event related fear, distress, and maladaptive coping. J Trauma Stress. 2005;18:631-6.

47. Knaevelsrud C, Maercker A. Does the quality of the working alliance predict treatment outcome in online psychotherapy for traumatized patients? J Med Internet Res. 2006;8:e31.

\section{Correspondence:}

Juliana Amaral Medeiros da Silva

Rua Luiz Afonso, 84 - Cidade Baixa (Escola de Saúde e Bem Estar - FADERGS)

90050-310 - Porto Alegre, RS - Brazil

E-mail: julianaamedeiros.psicologia@gmail.com 